\title{
How Do Contaminated Reservoir Bottom Sediments Affect Water Quality? An Assessment Using SWIM Model
}

\author{
Şebnem Elçi $i^{1^{*}}$, Sinem Elif Şimşek ${ }^{1}$
}

\begin{abstract}
In this study, an approach for the assessment of long term effects of contaminated sediments on the surface water quality of a future reservoir is presented. A one-dimensional sediment-water interaction model designed to simulate contaminants associated with the sediments, and the transfer of these contaminants to the overlying water column, was developed. The effect of contaminated bottom sediments on water quality was investigated under different stratification conditions. The numerical model was applied to an existing reservoir (Tahtalı Reservoir) for validation and projected contaminant concentrations based on the soil and water samples collected before inundation of the land. Results were compared with the concentrations obtained from water samples collected during its operation. Next, transfer to a planned reservoir (Çamlı Basin, Izmir) of four heavy metals-copper, zinc, chromium, and lead-existing in bottom sediments of the planned reservoir is modeled. A ten year projection of heavy metal concentrations for the Çamlı Reservoir showed concentrations to be higher than those acceptable by the World Health Organization (WHO). Construction of a treatment facility is recommended if the reservoir is to be utilized for providing domestic water. Water Environ. Res., 85 (2013).
\end{abstract}

KEYWORDS: 1-D sediment-water interaction model, reservoir water quality, SWIM, heavy metals, Çamlı Reservoir, Turkey, bottom sediments.

doi:10.2175/WER-D-12-00321.1

\section{Introduction}

A new sediment-water interaction model, based on existing sediment water interaction models proposed by Ruiz et al. (2001) and Gualtieri (2001), was developed and used to study the interaction between contaminant and aquatic environments. Interaction of the water column with bed sediments is a key process in water quality modeling for environmental contaminants, including heavy metals. Numerical models simulating the sediment-water interaction can be used to understand the behavior of pollutants in lakes and reservoirs, and to develop different strategies to remediate the pollutants. Metal interactions between sediment and water play a critical role in effectiveness of remediation efforts, especially for watersheds that have been effected by mining.

In the literature, several models are available and used for modeling water quality evaluation in watersheds (i.e., BASINS, HSPF, QUAL2E). However, these models are not capable of modeling metals fate and transport processes (Caruso, 2004).

$1^{*}$ Department of Civil Engineering, Izmir Institute of Technology, Urla, Izmir, Turkey; email: sebnemelci@iyte.edu.tr.
Other models which evaluate the equilibrium of metal species concentrations based on detailed $\mathrm{pH}$ and geochemical information include MINTEQ and WATEQ, which do not consider advective transport of metals. A sediment flux model developed by Di Toro (2001) solves mass balance equations for nitrogen, phosphorus, silica, carbon, and oxygen. The inputs are particulate organic matter from the overlying water column, together with the necessary dissolved concentrations as boundary conditions. Few models, including WASP (Ambrose et al., 1993), RECOVERY (Ruiz et al., 2001), and a model developed by Gualtieri (2001), are capable of modeling sediment-water interaction and metals concentrations, loadings, and transport. The existing sediment-water column interaction models assume that the system is idealized. The models assume a well mixed surface water layer above a mixed sediment column, and below the mixed sediment column, two layers composed of both contaminated and clean deep sediment layers. This assumption does not reflect the true environment, because almost all lakes and reservoirs experience thermal stratification.

Recently, a large number of lake ecosystem modelers established a group to develop the General Lake Model (GLM), an open source lake model (Hipsey et al., 2012). The Aquatic Ecodynamics module of the GLM, which simulates nutrients and oxygen dynamics, includes sediment-water interactions. The sediment routines allow the simulation of benthic oxygen consumption, and the release of nutrients and metal ions as a function of prevailing reduction-oxidation conditions at the sediment-water interface.

This paper provides an overview of a newly developed onedimensional sediment-water interaction model (SWIM), and discusses the sensitivity of model results to important parameters. The model results for the monitored dichlorodiphenyldichloroethylene (DDE) concentrations and the modeled dieldrin concentrations were evaluated with the RECOVERY model. Calibration and validation of the model using the data collected at an existing reservoir, before and after inundation of the land, is then described. Two reservoirs in Izmir were selected for this study: (1) the Tahtall Reservoir which is currently in operation, and (2) the Çamlı Reservoir, the construction of which is being planned by the Izmir Water and Sewerage Authority. Both reservoirs are intended to supply drinking water to Izmir, which has a population of over three million with a $1.5 \%$ annual growth rate, and is the fastest growing city in West Anatolia. The model is then applied to the reservoirs to simulate the transfer of 


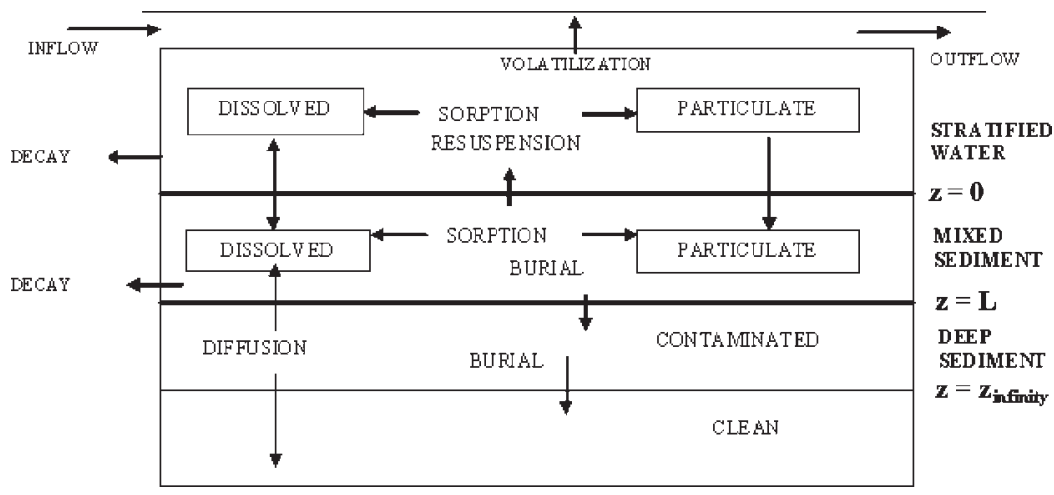

Figure 1-Theoretical representation of sediment-water column interaction model.

contaminants associated with the sediments to the overlying water column over time.

\section{Methodology}

The SWIM Model. In one dimension, the modeled system is idealized as three layers in a reservoir: the water layer, the mixed sediment layer, and the deep sediment layer (Figure 1). In the model, contaminant concentrations are assumed to vary in a vertical direction only. Contaminants in the water column can be in particulate and dissolved forms. Linear equilibrium sorption of particles is allowed. Volatilization and decaying of contaminants are considered at constant rates. Sediments are considered as the only source of contamination to the water body. Flow through the water column is assumed constant. The settling, resuspension, and diffusion of the contaminants are the exchange mechanisms between the water layer and the mixed layer. Diffusion and burial are considered for exchange of contaminants between the mixed layer and the deep sediment layer. Following Boyer et al. (1994), the mass balance equations utilized in the model are defined.

For contaminants in the water column, the mass balance equation can be written as:

$$
\begin{aligned}
\operatorname{Vol}_{w} \times \frac{d C_{w}}{d t}= & Q \times C_{i}-Q \times C_{w}-k_{w} \times V_{o l} \times C_{w} \\
& -V_{s} \times A_{w} \times F_{p w} C_{w}+V_{r} \times A_{m} \times C_{m} \\
& +D_{s w} \times A_{m}\left(F_{d p} \times C_{m}-F_{d w} \times C_{w}\right)+W
\end{aligned}
$$

where $\operatorname{Vol}_{w}$ is the volume of water body $\left(\mathrm{m}^{3}\right), C_{w}$ and $C_{m}$ are the concentration of contaminants for both water and mixed layers, respectively $\left(\mu \mathrm{g} / \mathrm{m}^{3}\right), t$ is the time (year), $Q$ is the flow rate $\left(\mathrm{m}^{3} /\right.$ year), $C_{i}$ is the inflow concentration $\left(\mu \mathrm{g} / \mathrm{m}^{3}\right), k_{w}$ is the decay rate constant of contaminants for the water column (year ${ }^{-1}$ ), $V_{s}$ and $V_{r}$ are the settling and resuspension velocities of particles, respectively (m/year), $A_{w}$ and $A_{m}$ are the surface areas of water and mixed sediment layers, respectively $\left(\mathrm{m}^{2}\right), F_{d p}$ is the contaminant concentration rate in sediment pore water to contaminant concentration in total sediment, $F_{d w}$ is the fraction of contaminant concentration in dissolved form, $F_{p w}$ is the ratio of contaminant which is in the particulate form in the water layer, $D_{s w}$ is the diffusion mass transfer coefficient at the sediment-water interface (m/year), and $W$ is the external loading ( $\mu \mathrm{g} /$ year).

The mass balance equation for the mixed sediment layer can be written as:

$$
\begin{aligned}
\operatorname{Vol}_{m} \times \frac{d C_{m}}{d t}= & -k_{m} \times \operatorname{Vol}_{m} \times C_{m}+V_{s} \times A_{w} \times F_{p w} \times C_{w} \\
& -V_{r} \times A_{m} \times C_{m}-V_{b} \times A_{m} \times C_{m} \\
& +D_{s w} \times A_{m} \times\left(F_{d w} \times C_{w}-F_{d p} \times C_{m}\right) \\
& +D_{s w} \times A_{m} \times\left(F_{d p} \times C_{s 0}-F_{d p} \times C_{m}\right)
\end{aligned}
$$

where $\mathrm{Vol}_{m}$ is the volume of mixed layer $\left(\mathrm{m}^{3}\right), k_{m}$ is the decay rate constant of contaminant in the mixed layer (year ${ }^{-1}$ ), $V_{b}$ is the burial velocity of sediments ( $\mathrm{m} /$ year), and $C_{s 0}$ is the contaminant concentration at the top of the deep contaminated layer $\left(\mathrm{g} / \mathrm{m}^{3}\right)$. The initial condition of eq 2 can be stated as $C_{m}=$ $C_{m 0 \text {. }}$

The mass balance equation for both deep sediment and clean sediment layers can be formulized by using a one-dimensional advection-diffusion-decay equation. In order to calculate contaminant concentration in the deep sediment layer, the mass balance equation can be written as:

$$
\frac{\partial C_{s}}{\partial t}=\varphi \times F_{d p} \times D_{s} \times \frac{\partial^{2} C_{s}}{\partial z^{2}}-V_{b} \times \frac{\partial C_{s}}{\partial z}-k_{s} \times C_{s}
$$

where $C_{s}$ is the contaminant concentration in the deep sediment layer $\left(\mathrm{g} / \mathrm{m}^{3}\right), \varphi$ is the sediment porosity, $D_{s}$ is the diffusion rate in sediment pore water ( $\mathrm{m}^{2} /$ year), $k_{s}$ is the decay rate constant of contaminants in the deep sediment layer (year ${ }^{-1}$ ), and $z$ is the depth into the sediment. At the top of the deep sediment, $z=0$ (m).

The initial condition, which is related to the mass balance equation for the deep and clean sediments layer, can be stated as:

- at mixed layer, $t=0 ; C_{s}=C_{s 0}$ (for the condition $\mathrm{L}>z>0$ ), and

- at deep layer, $t=0 ; C_{s}=0$ (for the condition $\infty>z>\mathrm{L}$ ).

The boundary condition which is related to the mass balance equation for the deep and clean sediments layer can be stated as:

- at deep layer, $z=\mathrm{L} ; J=J_{m s}$, and

- $z=\infty, \partial C_{s} / \partial z=0$.

Sediment characteristics significantly affect the behavior of contaminants. Therefore, calculation of settling, resuspension, and burial velocities has particular importance on modeling sediment-water interaction. The settling, resuspension, and burial velocity terms in the mass balance equations (eqs 1 through 3) are computed according to a steady state mass balance for the mixed layer solids (Boyer et al., 1994). Thus, for a 
given suspended solid concentration, the settling sediment mass is balanced by the net motion (considering both resuspension and burial) of the sediments in the mixed layer, as follows:

$$
0=V_{s} \times A_{w} \times S_{w}-\left(V_{r}+V_{b}\right) \times A_{m} \times(1-\varphi) \times \rho_{p}
$$

where $S_{w}$ is the suspended solid concentration $\left(\mu \mathrm{g} / \mathrm{m}^{3}\right)$, and $\rho_{p}$ is the density of particle $\left(\mathrm{g} / \mathrm{cm}^{3}\right)$. For calculating settling velocity, two different equations were selected and incorporated into the model:

(1) Stokes Settling Velocity (Yang, 2003),

$$
\begin{aligned}
V_{s}= & \frac{1.75 \times g}{v} \times \frac{\left(\rho_{p}-\rho_{w}\right)}{\rho_{w}} \times d^{2} \\
v= & 1.79^{2} \times 10^{-6} /\left(1+0.0337 \times T+0.000221 \times T^{2}\right) \\
\rho_{w}= & 10^{-3} \times(1-(T+288.9414) / \\
& \left.(508929.2 \times(T+68.12963)) \times(T-3.9863)^{2}\right)
\end{aligned}
$$

where $g$ is the gravitational acceleration $\left(\mathrm{m} / \mathrm{s}^{2}\right), v$ is the kinematic viscosity of the water $\left(\mathrm{m}^{2} / \mathrm{s}\right), T$ is the water temperature $\left({ }^{\circ} \mathrm{C}\right), d$ is the particle size $(\mathrm{mm})$, and $\rho_{w}$ is the density of water $\left(\mathrm{g} / \mathrm{cm}^{3}\right.$ ) (eq 5 is applicable for the estimation of the fall velocity of a sediment particle if the particle is equal to or less than 0.1 millimeter); and

(2) Rubey's Formula (Yang, 2003),

$$
V_{s}=F \times\left[1000 \times d \times g \times\left(\frac{\rho_{s}-\rho_{w}}{\rho_{w}}\right)\right]^{1 / 2}
$$

where $F=0.79$ for particles greater than one millimeter. For smaller particles, the following equation is used:

$$
\begin{aligned}
F= & {\left[\frac{2}{3}+\frac{36 \times v^{2}}{g \times d^{3} \times\left(\rho_{s} / \rho_{w}-1\right)}\right]^{1 / 2} } \\
& -\left[\left[\frac{36 \times v^{2}}{g_{*} d^{3} \times\left(\rho_{s} / \rho_{w}-1\right)}\right]^{1 / 2}\right]
\end{aligned}
$$

In the SWIM model, the burial velocity is calculated as a function of settling velocity (Boyer et al., 1994). The equation for calculation of the burial velocity is given as:

$$
V_{b}=\alpha \times V_{s}
$$

where $\alpha$ is the probability of deposition upon contact with the bed.

The SWIM model was developed based on the equations used in the existing sediment water interaction models (Ruiz et al., 2001; Gualtieri, 2001). However, the SWIM model has several features offering the researchers more flexible and realistic evaluation of contaminants. The SWIM model can simulate stratified surface water above a sediment column, which is the most common environment encountered in nature (Elçi, 2008; Çalışkan and Elçi, 2009). The user has the option to select between two settling velocity formulations according to the particle size, density, and viscosity of the water (eqs 5 and 9) which are calculated as a function of the temperature in the model (eqs 6 and 7). Moreover, the model has the capability of reverse modeling, enabling the prediction of projected contaminant concentrations of the water column in time, based on the monitored contaminant concentrations of the existing bed sediments at the reservoir site. The SWIM model was coded in Visual Basic software (Microsoft Corporation, Redmond, Washington). The coupled set of differential equations is solved numerically by the tridiagonal matrix algorithm, a simplified form of Gaussian elimination that can be used to solve tridiagonal systems of equations. In this algorithm, a first sweep eliminates the coefficients, and then an (abbreviated) backward substitution produces the solution (double sweep method).

The SWIM model is used to investigate the effect of inflow concentrations (Table 1). For this purpose, dieldrin is used because its model properties are found in published literature (Ruiz et al., 2001). Dieldrin is a persistent, bioaccumulative, and toxic pollutant targeted by U.S. EPA and does not break down easily the environment.

To test the sensitivity of the simulated concentrations to the initial concentration values, initial concentrations were increased from 0 to $1000 \mu \mathrm{g} / \mathrm{m}^{3}$. It was observed that the simulated concentration in the water layer remained the same, whereas in mixed and deep layers the values increased by up to $36 \%$ (Table 2). Similarly, sensitivity of the results to the inflow concentration was tested by increasing the inflow concentration. It was observed that when initial concentrations were doubled, the simulated concentrations also doubled. Porosity values are also found to be effective, and it was observed that simulated concentrations increased significantly as the porosity values used in the model increased.

Another important parameter in calculating the settling velocity is the density of water, which is a function of water temperature. To test the sensitivity of the simulated concentrations to temperature of the water, temperature of the mixed water column was increased from 15 to $30{ }^{\circ} \mathrm{C}$. It was observed that simulated concentrations increased in all three layers by 32 to $42 \%$. The predicted concentration values in the water column for the mixed case were compared with the predicted concentration values for stratified conditions having three water layers $\left(30{ }^{\circ} \mathrm{C}\right.$ for the epilimnion, $15{ }^{\circ} \mathrm{C}$ for the metalimnion, and $5{ }^{\circ} \mathrm{C}$ for the hypolimnion). The simulated concentration values in the water column further increased to values ranging from 37 to $52 \%$ (Table 3 )

Comparison of Projected Contaminant Concentration Simulated by the RECOVERY and SWIM Models. The only existing sediment-water interaction model tested with field data, the RECOVERY model, was used to compare simulated concentrations. The primary difference between the RECOVERY and SWIM models is how contaminant concentration is predicted in the water column. Settling and burial velocities are set to constant values in the RECOVERY model, rather than being calculated using the settling velocity equations defined in this study. Also, the water column is assumed mixed in the RECOVERY model, whereas the SWIM model can simulate stratified conditions, which is the most common case in lakes and reservoirs.

The SWIM model is used to predict dieldrin concentrations in all three layers using parameters from the literature (Table 1). The results are compared to the results of the RECOVERY model for the same conditions. The SWIM and RECOVERY model results of contaminant concentrations were similar for the three simulated layers (Figures 2 through 4). The computed error measures were calculated based on results simulated by the RECOVERY model. Results for the water column were 0.0022 
Table 1-Values of parameters for SWIM model for simulation of dieldrin concentration.

\begin{tabular}{|c|c|c|}
\hline Parameters & Unit & Value \\
\hline$Q$ (flow rate) & $\mathrm{m}^{3}$ & $2 \times 10^{7}$ \\
\hline Vol $_{w}$ (volume of water body) & $\mathrm{m}^{3}$ & $1 \times 10^{8}$ \\
\hline $\mathrm{Vol}_{m}$ (volume of mixed layer) & $m^{3}$ & $1 \times 10^{7}$ \\
\hline$A_{w}$ (surface area of water) & $m^{2}$ & $1 \times 10^{7}$ \\
\hline$A_{m}$ (surface area of mixed sediment layer) & $m^{2}$ & $1 \times 10^{7}$ \\
\hline$k_{w}$ (decay rate constant of contaminant for water) & 1/year & 0.22 \\
\hline$k_{s}$ (decay rate constant of contaminants in deep sediment layer) & 1/year & 0 \\
\hline$C_{i}$ (inflow concentration) & $\mu \mathrm{g} / \mathrm{m}^{3}$ & 1000 \\
\hline$C_{w}$ (concentration of contaminant for water) & $\mu \mathrm{g} / \mathrm{m}^{3}$ & 1000 \\
\hline$C_{w 0}$ (initial concentration of contaminant for water) & $\mu \mathrm{g} / \mathrm{m}^{3}$ & 0 \\
\hline$C_{m}$ (concentration of contaminant for mixed layers) & $\mu \mathrm{g} / \mathrm{m}^{3}$ & Dependent on $C_{w}$ \\
\hline$C_{s}$ (contaminant concentration in deep sediment layer) & $\mu \mathrm{g} / \mathrm{m}^{3}$ & Dependent on $C_{m}$ \\
\hline$C_{s o}$ (contaminant concentration at top of deep contaminated layer) & $\mu \mathrm{g} / \mathrm{m}^{3}$ & Dependent on $C_{m}$ \\
\hline$S_{w}$ (suspended solid concentration) & $\mu \mathrm{g} / \mathrm{m}^{3}$ & 1000 \\
\hline$V_{s}$ (settling velocity of particles) & $\mathrm{m} /$ year & Calculated \\
\hline$V_{r}$ (resuspension velocity of particles) & $\mathrm{m} /$ year & Calculated \\
\hline$V_{b}$ (burial velocity) & $\mathrm{m} /$ year & Calculated \\
\hline$F_{d w}$ (fraction of contaminant concentration in dissolved form) & & 0.606 \\
\hline$F_{p w}$ (ratio of contaminant in particulate form in water layer) & & 0.393 \\
\hline$\varphi$ (sediment porosity) & & 0.7 \\
\hline$\rho_{p}$ (density of particle) & $\mathrm{g} / \mathrm{cm}^{3}$ & $2.65 \times 10^{9}$ \\
\hline$\rho_{w}$ (density of water) & $\mathrm{g} / \mathrm{cm}^{3}$ & Calculated \\
\hline$V_{d}$ (diffusive mass transfer coefficient) & m/year & $1.4406 \times 10^{-6}$ \\
\hline
\end{tabular}

$\mu \mathrm{g} / \mathrm{L}, 0.0018 \mu \mathrm{g} / \mathrm{L}$, and $10.26 \%$ for the root mean square error (RMSE), the mean absolute error (MAE), and the mean relative error (MRE), respectively. Results for the mixed layer were 8.69 $\times 10^{-4} \mathrm{mg} / \mathrm{kg}, 0.00073 \mathrm{mg} / \mathrm{kg}$, and $23.3 \%$ for RMSE, MAE, and MRE, respectively. Results for the deep layer were $180.3 \mu \mathrm{g} / \mathrm{m}^{3}$, $143.6 \mu \mathrm{g} / \mathrm{m}^{3}$, and $13.6 \%$ for RMSE, MAE, and MRE, respectively.
The study by Ruiz et al. (2001) applied the RECOVERY model to analyze a field scale experiment in which a flooded limestone quarry was dosed with the insecticide DDE. The quarry was treated with DDE at a concentration of $0.2 \mathrm{mg} / \mathrm{m}^{3}$ to the epilimnion. The quarry was then analyzed after treatment, and the results showed that, essentially, all of the DDE was initially

Table 2-Results of sensitivity analysis for initial and inflow concentrations and porosity. Percent changes with respect to parameters kept constant (marked as bold) show how much predicted concentration value varies for different values of parameters.

\begin{tabular}{|c|c|c|c|c|c|}
\hline \multicolumn{2}{|c|}{ Initial concentration $\left(\mu \mathrm{g} / \mathrm{m}^{3}\right)$} & \multicolumn{2}{|c|}{ Inflow concentration $\left(\mu \mathrm{g} / \mathrm{m}^{3}\right)$} & \multicolumn{2}{|c|}{ Porosity } \\
\hline$C_{i 1}{ }^{\mathrm{a}}$ & 0 & $C_{i n f 1}{ }^{\mathrm{b}}$ & $1.0 \times 10^{5}$ & $\varphi_{i 1}{ }^{\mathrm{c}}$ & 0.7 \\
\hline$C_{i 2}$ & 1000 & $C_{\text {inf2 }}$ & $1.0 \times 10^{6}$ & $\varphi_{i 2}$ & 0.2 \\
\hline$C_{i 3}$ & 500 & $C_{\text {inf3 }}$ & $5.0 \times 10^{5}$ & $\varphi_{i 3}$ & 0.5 \\
\hline$C_{w 1}^{d}$ & 0.021 & $C_{w 1}$ & 2.13 & $C_{w 1}$ & 0.021 \\
\hline$C_{w 2}$ & 0.021 & $C_{w 2}$ & 21.3 & $C_{w 2}$ & 0.005 \\
\hline$C_{w 3}$ & 0.021 & $C_{w 3}$ & 10.67 & $C_{w 3}$ & 0.0115 \\
\hline$\% C_{w 1-2}$ & & $\%_{1-2}$ & 900 & $\% C_{w} 1-2$ & 76.2 \\
\hline$\% C_{w 1-3}$ & & $\%_{1-3}$ & 49.9 & $\% C_{w} 1-3$ & 45.2 \\
\hline$C_{m 1}{ }^{\mathrm{e}}$ & 0.009 & $C_{m 1}$ & 0.89 & $C_{m 1}$ & 0.009 \\
\hline$C_{m 2}$ & 0.01 & $C_{m 2}$ & 8.91 & $C_{m 2}$ & 0.003 \\
\hline$C_{m 3}$ & 0.0096 & $C_{m 3}$ & 4.5 & $C_{m 3}$ & 0.005 \\
\hline$\% C_{m 1-2}$ & 11.1 & $\%_{1-2}$ & 901 & $\% C_{m} 1-2$ & 66.7 \\
\hline$\% C_{m 1-3}$ & 6.7 & $\%_{1-3}$ & 49.9 & $\% C_{m 1-3}$ & 44.4 \\
\hline $\boldsymbol{C}_{\boldsymbol{s} \mathbf{1}}{ }^{1-3}$ & 7095 & $C_{s 1}$ & $7.0 \times 10^{5}$ & $\boldsymbol{C}_{\boldsymbol{s} 1}$ & 7095 \\
\hline$C_{s 2}$ & 10386 & $C_{s 2}$ & $7.0 \times 10^{6}$ & $C_{s 2}$ & 1418 \\
\hline$C_{s 3}$ & 8741 & $C_{s 3}$ & $3.5 \times 10^{6}$ & $C_{s 3}$ & 3698 \\
\hline$\% C_{S 1-2}$ & 36.3 & $\% C_{s} 1-2$ & 900 & $\% C_{s} 1-2$ & 80 \\
\hline$\% C_{s} 1-3$ & 23.2 & $\% C_{s} 1-3$ & 49.9 & $\% C_{s} 1-3$ & 47.8 \\
\hline
\end{tabular}

\footnotetext{
${ }^{\mathrm{a}} C_{i}=$ initial concentration.

${ }^{\mathrm{b}} C_{\text {inf }}=$ inflow concentration.

${ }^{\mathrm{c}} \varphi_{i}=$ porosity.

${ }^{d} C_{w}=$ contaminant concentration in the water layer.

${ }^{\mathrm{e}} C_{m}=$ contaminant concentration in the mixed layer.

${ }^{f} C_{s}=$ contaminant concentration in the deep sediment layer.
}

Water Environment Research, Volume 85-Copyright (c) 2013 Water Environment Federation Uncorrected Page Proofs 
Table 3-Sensitivity analysis results of water temperature on simulated concentrations.

\begin{tabular}{|c|c|c|c|}
\hline \multicolumn{2}{|c|}{ Mixed water column } & \multicolumn{2}{|c|}{ Stratified water column } \\
\hline$T_{1}^{\mathrm{a}}\left({ }^{\circ} \mathrm{C}\right)$ & 15 & Constant $T\left({ }^{\circ} \mathrm{C}\right)$ & 15 \\
\hline$T_{2}\left({ }^{\circ} \mathrm{C}\right)$ & 30 & Varying $T\left({ }^{\circ} \mathrm{C}\right)$ & $30,15,5$ \\
\hline$C_{w 1} \mathrm{~b}^{\prime}$ & 0.019 & $C_{w 1}$ & 0.019 \\
\hline$C_{w 2}$ & 0.025 & $C_{w 2}$ & 0.026 \\
\hline$\% C_{w}$ change & 31.6 & $\% C_{w}$ change & 36.8 \\
\hline$C_{m 1}{ }^{c}$ & $6.40 \times 10^{-7}$ & $C_{m 1}$ & $6.40 \times 10^{-7}$ \\
\hline$C_{m 2}$ & $9.10 \times 10^{-7}$ & $C_{m 2}$ & $9.70 \times 10^{-7}$ \\
\hline$\% C_{m}$ change & 42.2 & $\% C_{m}$ change & 51.5 \\
\hline$C_{s 1} \mathrm{~d}$ & 1.3 & $C_{s 1}$ & 1.3 \\
\hline$C_{s 2}$ & 1.847 & $C_{s 2}$ & 1.963 \\
\hline$\% C_{s}$ change & 42 & $\% C_{s}$ change & 50.9 \\
\hline
\end{tabular}

a $T=$ temperature.

${ }^{b} C_{w}=$ contaminant concentration in the water layer.

${ }^{c} C_{m}=$ contaminant concentration in the mixed layer.

${ }^{\mathrm{d}} C_{S}=$ contaminant concentration in the deep sediment layer.

released in the epilimnion. The quarry was periodically sampled, and the results were used to validate the numerical model. The comparison of the SWIM and RECOVERY models predicted DDE concentrations, and observed that DDE concentrations were reasonable (Figures 5 and 6). There was no observed data for the deep sediment layer (Figure 7).

Application of the SWIM Model to the Tahtalı and Çamlı Reservoirs. The SWIM model was first applied to the Tahtal Reservoir, and the projected contaminant concentration values were modeled based on the soil and water samples collected before inundation of the land in 1996. The primary characteristics of the basin are given in Table 4. The predicted concentrations were compared with the monitored water samples during operation in 2006. The maximum values of the concentrations monitored along the Sasal and Tahtalı rivers (the two primary rivers of the Tahtalı Reservoir), were selected and used as initial concentrations in the water column, and as inflow concentrations using the SWIM model. Initial contaminant concentrations of the deep layer are set to the values determined from the analysis of the sediment samples. Other parameters, such as density of sediment solids, molecular diffusivity, porosity, and decay rate, are obtained from the literature (U.S. EPA, 2005).

A reverse modeling approach was applied for the prediction of contaminant concentration in the water column originating from the bottom sediments. In this approach, the contaminants at the bottom sediment layer are considered as the initial condition, and two modules are utilized. Using the first module,

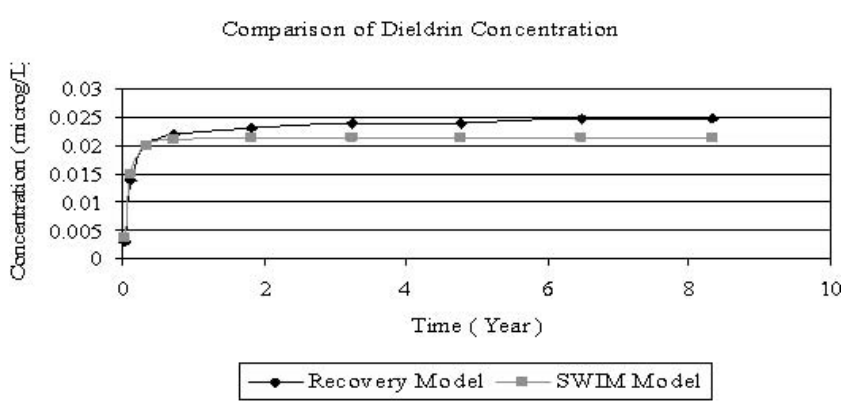

Figure 2-Dieldrin concentration in water column simulated by RECOVERY and SWIM models. heavy metal concentrations monitored in the dam site sediments are assumed as initial deep layer concentrations, and mixed sediment layer concentrations are calculated using the mass balance equation. Initial concentration of contaminants for the mixed sediment layer is assumed equal to the contaminant concentration in water, which is obtained from the measurements. Once the concentration in the mixed layer is calculated using the mass balance equation for the mixed layer, this value is set equal to the water column concentration at the boundary. The mass balance equation for the water column is then solved to calculate water column concentrations. Using the second module, initial contaminant concentration in the water column and inflow contaminant concentration were considered together with the contaminant concentration, because of the deep layer concentration calculated as described in the first module. The mass balance equation for the mixed sediment layer and the advection-diffusion-decay equation for the deep sediment layer were then solved. These processes were repeated for each time interval of 0.5 year with a time step of 0.05 year.

\section{Results}

The transfer of four heavy metals-copper, zinc, chromium, and lead-existing in bottom sediments of reservoir water in the Tahtalı Basin was modeled with the reverse model described above (Tables 5 and 6). Based on 1996 sediment concentrations

Comparison of Dieldrin Concentration

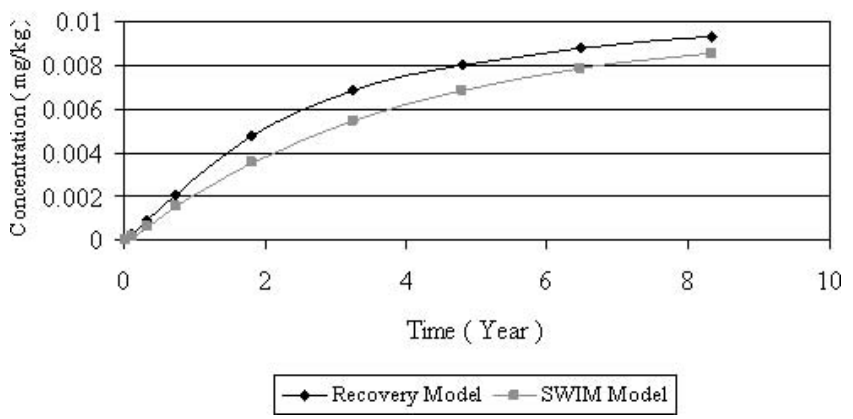

Figure 3-Simulated dieldrin concentration in mixed layer simulated by RECOVERY and SWIM models.

Water Environment Research, Volume 85-Copyright @ 2013 Water Environment Federation Uncorrected Page Proofs 
Dieldrin Concentration in Deep Layer

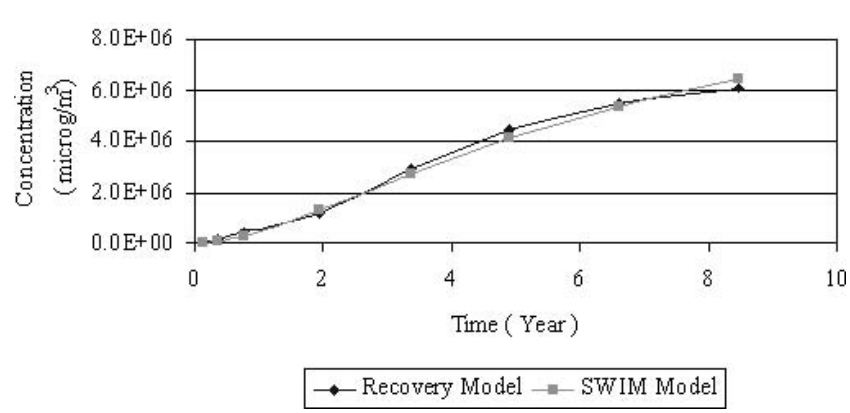

Figure 4-Dieldrin concentration in deep sediment layer simulated by RECOVERY and SWIM models.

(corresponding to conditions before construction of the dam), the predicted concentration of copper in the water for year 2006 was $0.006 \mathrm{mg} / \mathrm{L}$. Minimum and maximum values monitored during 2006 varied between 0.001 and $0.015 \mathrm{mg} / \mathrm{L}$. Simulated zinc concentrations reached $0.072 \mathrm{mg} / \mathrm{L}$, whereas minimum and maximum values monitored during 2006 varied between 0.008 and $0.169 \mathrm{mg} / \mathrm{L}$. Simulated concentration values for chromium and lead were $0.0017 \mathrm{mg} / \mathrm{L}$ and $0.007 \mathrm{mg} / \mathrm{L}$, respectively. Minimum and maximum monitored values varied between 0.001 and $0.002 \mathrm{mg} / \mathrm{L}$ for chromium, and 0.001 and $0.003 \mathrm{mg} / \mathrm{L}$ for lead. These results showed that the SWIM model can correctly predict heavy metal concentrations. These concentrations are well below the limits set by the World Health Organization (WHO) for water quality standards $(0.05 \mathrm{mg} / \mathrm{L}$ for copper, $5 \mathrm{mg} / \mathrm{L}$ for zinc, $0.05 \mathrm{mg} / \mathrm{L}$ for chromium, and 0.1 $\mathrm{mg} / \mathrm{L}$ for lead).

The SWIM model was then applied to the Çamlı Reservoir (a neighboring basin) to predict the long term impact of the contaminants attached to the site sediments on water quality. For this purpose, results of soil samples taken and analyzed before construction of the dam were obtained from the literature (Mutlu, 2004), as shown in Tables 5 and 6. Prediction results over a ten year period showed that the copper concentration in the water layer reached $0.64 \mathrm{mg} / \mathrm{L}$ based on the initial copper concentration of $36.2 \mathrm{mg} / \mathrm{L}$ measured in the sediments. The concentration of zinc in the water layer was projected to be 141 $\mathrm{mg} / \mathrm{L}$ based on the initial zinc concentration of $781 \mathrm{mg} / \mathrm{L}$ measured in the sediments. The concentration of chromium in the water layer was projected to be $30.2 \mathrm{mg} / \mathrm{L}$ based on the

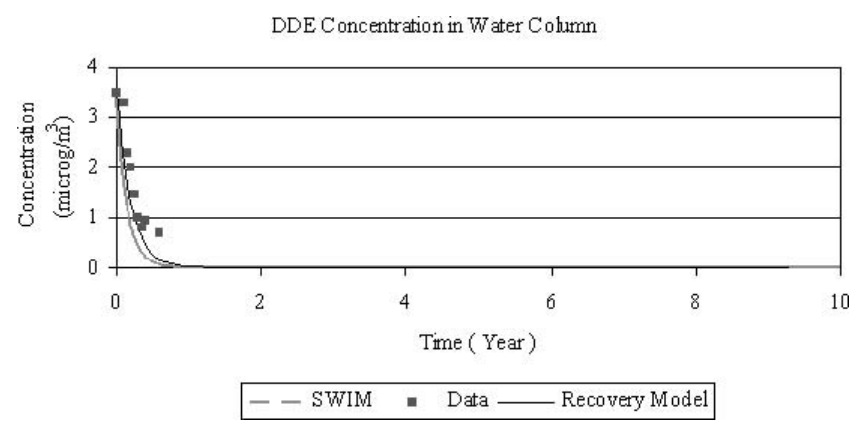

Figure 5-Comparison of simulated dichlorodiphenyldichloroethylene (DDE) concentrations for water column.
DDE Concentration in Mixed Layer

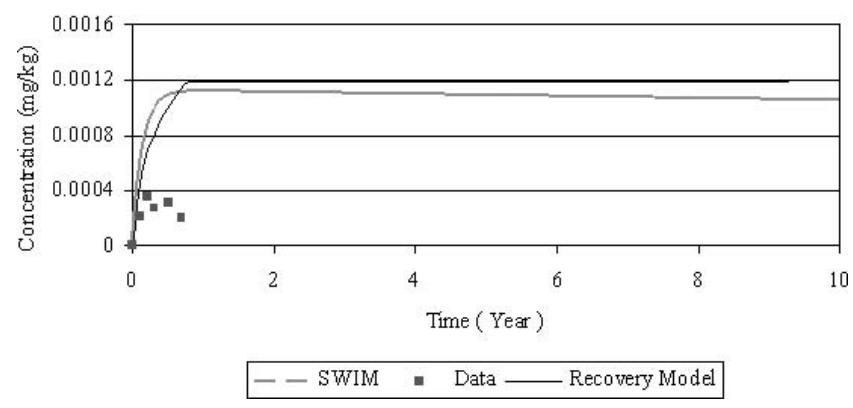

Figure 6-Comparison of simulated dichlorodiphenyldichloroethylene (DDE) concentrations for mixed sediment layer.

initial chromium concentration of $197 \mathrm{mg} / \mathrm{L}$ measured in the sediments. And, the concentration of lead in the water layer was projected to be $278 \mathrm{mg} / \mathrm{L}$ based on the initial lead concentration of $446 \mathrm{mg} / \mathrm{L}$ measured in the sediments (Figure 8).

Finally, the reverse model was applied to the study site considering that stratification occured during some periods of each year for the projected ten years. Based on water temperature measurements taken at another reservoir (Elçi, 2008), the water column was divided into three layers: the epilimnion (upper warm layer) with a temperature of $25^{\circ} \mathrm{C}$, the thermocline with a temperature of $15^{\circ} \mathrm{C}$, and the hypolimnion (lower cold layer) with a temperature of $5{ }^{\circ} \mathrm{C}$. Application of the reverse model to the stratified water conditions indicated that the stratified layer behaves as a barrier for the transport of metals to the upper column, resulting in less projected contaminant concentrations at the water column over ten years. Projected concentrations over ten years are 0.511, 112, 29.2, and $241 \mathrm{mg} / \mathrm{L}$ for copper, zinc, chromium, and lead, respectively (Figure 8). As these concentrations are higher than the acceptable limits provided by WHO, it was concluded that a treatment facility would be necessary if this reservoir is to be utilized for providing domestic water to the city of Izmir.

\section{Conclusions}

In this study, the impact of submersed contaminated bottom sediments on surface water quality was investigated through a newly developed SWIM model based on existing sedimentwater interaction models (Ruiz, 2001; Gualtieri, 2001). Unlike the existing sediment-water column interaction models that

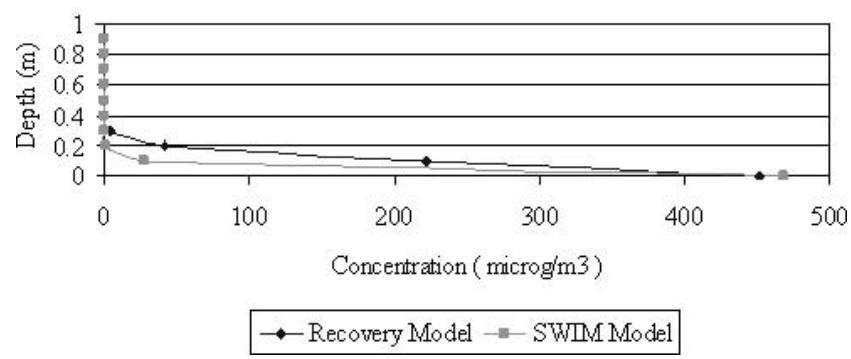

Figure 7-Comparison of simulated dichlorodiphenyldichloroethylene (DDE) concentrations for deep sediment layer.

\section{Water Environment Research, Volume 85-Copyright (c) 2013 Water Environment Federation Uncorrected Page Proofs}


Table 4-Characteristics of Tahtalı and Çamlı Reservoirs.

\begin{tabular}{|c|c|c|c|}
\hline Reservoir / basin property & Unit & Tahtalı & Çamlı \\
\hline Drainage basin area & $\mathrm{km}^{2}$ & 546 & 62 \\
\hline Average amount of water (annual) & $\mathrm{m}^{3}$ & $153 \times 10^{6}$ & $22.54 \times 10^{6}$ \\
\hline Height from river bed & $\mathrm{m}$ & 54.5 & 75 \\
\hline Annual available domestic water supply & $\mathrm{m}^{3}$ & 128 & $21.50 \times 10^{6}$ \\
\hline Height of dam & $\mathrm{m}$ & 62.5 & 91 \\
\hline Embankment type & & Rock fill & Rock fill \\
\hline Thalweg elevation & $\mathrm{m}$ & 54.5 & 85 \\
\hline Crest level of dam & $\mathrm{m}$ & 62.5 & 160 \\
\hline Minimum operation level of reservoir & $\mathrm{m}$ & 31 & 105 \\
\hline Normal operation level of reservoir & $\mathrm{m}$ & 60.5 & 156 \\
\hline Maximum water elevation of reservoir & $\mathrm{m}$ & 60.5 & 157.66 \\
\hline Surface area of reservoir (at normal water elevation) & $\mathrm{km}^{2}$ & 23.52 & 0.85 \\
\hline Reservoir volume at minimum water surface elevation & $\mathrm{m}^{3}$ & $19.60 \times 10^{6}$ & $1.28 \times 10^{6}$ \\
\hline Reservoir volume at normal water surface elevation & $\mathrm{m}^{3}$ & $306.65 \times 10^{6}$ & $23.98 \times 10^{6}$ \\
\hline Reservoir volume at maximum water surface elevation & $m^{3}$ & $306.65 \times 10^{6}$ & $25.36 \times 10^{6}$ \\
\hline Active volume of reservoir & $m^{3}$ & $287.05 \times 10^{6}$ & $22.71 \times 10^{6}$ \\
\hline
\end{tabular}

Table 5-Values of parameters used in SWIM model for simulation of heavy metal concentrations.

\begin{tabular}{|c|c|c|c|}
\hline Parameters & Unit & Tahtalı & Çamlı \\
\hline$Q$ (flow rate) & $\mathrm{m}^{3}$ & $153 \times 10^{6}$ & $22.54 \times 10^{6}$ \\
\hline $\mathrm{Vol}_{w}$ (volume of water body) & $\mathrm{m}^{3}$ & $306.65 \times 10^{6}$ & $23.98 \times 10^{6}$ \\
\hline $\mathrm{Vol}_{m}$ (volume of mixed layer) & $\mathrm{m}^{3}$ & $23.52 \times 10^{6}$ & $854 \times 10^{3}$ \\
\hline$A_{w}$ (surface area of water) & $\mathrm{m}^{2}$ & $23.52 \times 10^{6}$ & $854 \times 10^{3}$ \\
\hline$A_{m}$ (surface area of mixed sediment layer) & $m^{2}$ & $23.52 \times 10^{6}$ & $854 \times 10^{3}$ \\
\hline$k_{w}$ (decay rate constant of contaminant for water) & 1/year & Depends on type of heavy metal & Depends on type of heavy metal \\
\hline$k_{s}$ (decay rate constant of contaminants in deep sediment layer) & 1/year & Depends on type of heavy metal & Depends on type of heavy metal \\
\hline$C_{m}$ (concentration of contaminant for mixed layers) & $\mu \mathrm{g} / \mathrm{m}^{3}$ & Depends on $C_{W}{ }^{a}$ & Depends on $C_{W}$ \\
\hline$C_{s}$ (contaminant concentration in deep sediment layer) & $\mu \mathrm{g} / \mathrm{m}^{3}$ & Depends on $C_{m}$ & Depends on $C_{m}$ \\
\hline$C_{s o}$ (contaminant concentration at top of the deep sediment layer) & $\mu \mathrm{g} / \mathrm{m}^{3}$ & Depends on $C_{m}$ & Depends on $C_{m}$ \\
\hline$S_{w}$ (suspended solid concentration) & $\mu \mathrm{g} / \mathrm{m}^{3}$ & 100 & 100 \\
\hline$V_{s}$ (settling velocity of particles) & m/year & Calculated & Calculated \\
\hline$V_{r}$ (resuspension velocity of particles) & m/year & Calculated & Calculated \\
\hline$V_{b}$ (burial velocity) & $\mathrm{m} /$ year & Calculated & Calculated \\
\hline$F_{d w}$ (fraction of contaminant concentration in dissolved form) & & Calculated & Calculated \\
\hline$F_{p w}$ (ratio of contaminant in particulate form in water layer) & & Calculated & Calculated \\
\hline$\varphi$ (sediment porosity) & & 0.7 & 0.7 \\
\hline$\rho_{w}$ (density of water) & $\mathrm{g} / \mathrm{cm}^{3}$ & Calculated & Calculated \\
\hline
\end{tabular}

${ }^{\mathrm{a}} C_{w}=$ contaminant concentration in the water layer.

assume the system is idealized as a well mixed surface water layer above a stratified sediment column, the SWIM model can simulate stratified surface water which is the most common environment encountered in the nature. Additionally, the SWIM model has the capability of selecting between two different settling velocities (using Rubey's Formula and Stokes Settling Velocity) and calculates the corresponding resuspension velocities based on the mass balance equation.
The model presented has many limitations and eventually needs to be integrated with a three-dimensional hydrodynamic model. Currently, it does not allow for advection or dispersion in a horizontal direction, which are dominant processes when an inflow enters a reservoir. Also, vertical mixing controlled by the balance between stratification and wind induced shear affecting the transport of suspended and dissolved substances is not modeled. Further improvements are needed to model the

Table 6-Properties of selected heavy metal concentrations used in SWIM model.

\begin{tabular}{|c|c|c|c|c|}
\hline Heavy metal & Copper & Zinc & Chromium & Lead \\
\hline Initial concentration in the water column (mg/L) & 0.001 & 0.233 & 0.089 & 0.506 \\
\hline Initial concentration in deep sediment layer (mg/L) & 36.2 & 781 & 197.2 & 445.7 \\
\hline Inflow Concentration (mg/L) & 0.001 & 0.027 & 0.089 & 0.506 \\
\hline Molecular Diffusivity $\left(\mathrm{cm}^{2} / \mathrm{s}\right)$ & $5.42 \times 10^{-6}$ & $5.29 \times 10^{-6}$ & $4.39 \times 10^{-6}$ & $6.99 \times 10^{-6}$ \\
\hline Density of Sediment Solids $\left(\mathrm{g} / \mathrm{cm}^{3}\right)$ & 8.96 & 7.14 & 6.90 & 11.34 \\
\hline
\end{tabular}

Water Environment Research, Volume 85-Copyright (c) 2013 Water Environment Federation Uncorrected Page Proofs 

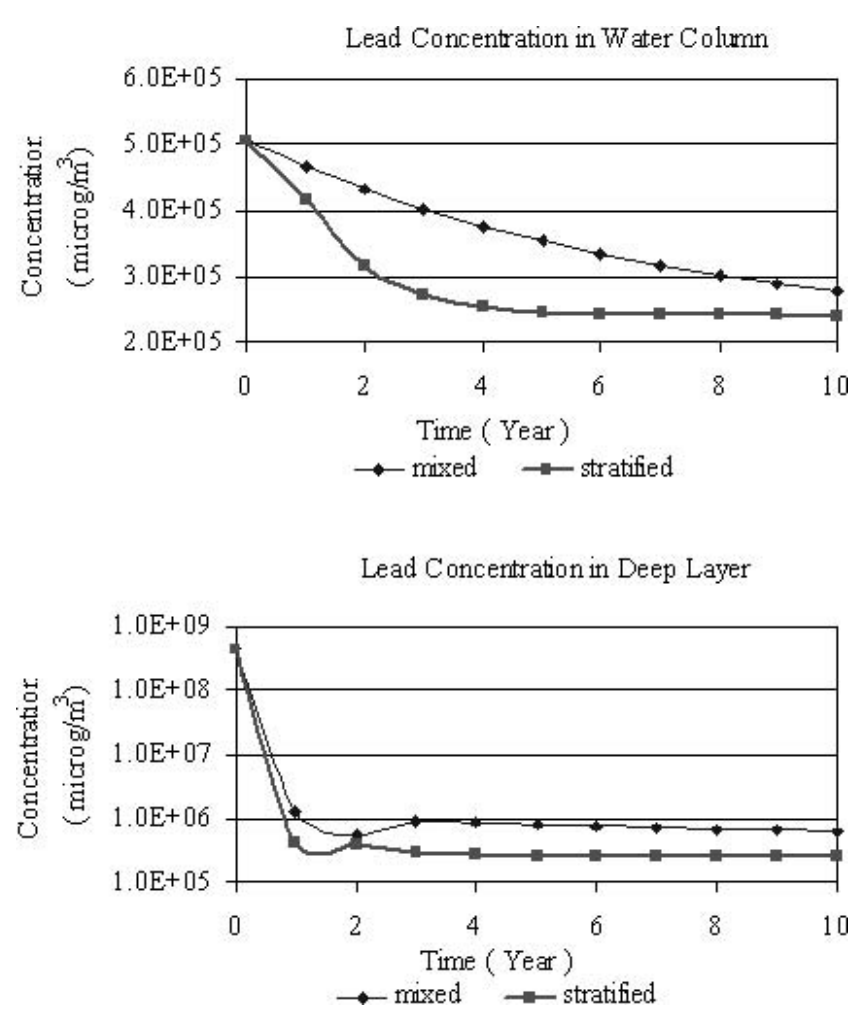

Figure 8-Lead concentration in water column and in deep sediment layer simulated by SWIM model for: (a) mixed water column, and (b) stratified water column.

transport of suspended and dissolved substances among horizontal cells specified for the reservoir.

The SWIM model is applied to the existing Tahtalı Reservior and the planned Çaml 1 Reservoir to predict the long-term impact of contaminants attached to the site sediments on water quality. Results of the reverse model used to predict contaminant concentrations in the water column originating from the bottom sediments indicated that heavy metal concentrations in the water layer of the Tahtal1 Reservoir could be predicted correctly $(0.006,0.072,0.0017$, and $0.007 \mathrm{mg} / \mathrm{L}$ for copper, zinc, chromium, and lead, respectively).

Projection of heavy metal concentrations for the Caml Reservoir over ten years, however, results in concentrations of $0.511,112,29.2$, and $241 \mathrm{mg} / \mathrm{L}$ for copper, zinc, chromium, and lead, respectively. As these concentrations are higher than the acceptable concentrations provided by WHO $(0.05 \mathrm{mg} / \mathrm{L}$ for copper, $5 \mathrm{mg} / \mathrm{L}$ for zinc, $0.05 \mathrm{mg} / \mathrm{L}$ for chromium, and $0.1 \mathrm{mg} / \mathrm{L}$ for lead), it was concluded that a treatment facility would be necessary if this reservoir is to be utilized for providing domestic water to the city of Izmir.

Submitted for publication-_; accepted for publication , .

\section{References}

Ambrose R. B.; Wool, T.; Martin J. L. (1993) Water Quality Analysis Simulation Program (WASP) User's Manual; U.S. Environmental Protection Agency, Environmental Research Laboratory: Athens, Georgia.

Boyer, J. M.; Chapra, S. C.; Ruiz, C. E.; Dortch, M. S. (1994) RECOVERY, a Mathematical Model to Predict the Temporal Response of Surface Water to Contaminated Sediments; Technical Report W-94-4; U.S. Army Corps of Engineers, Waterways Experiment Station: Vicksburg, Mississippi.

Çalışkan, A.; Elçi, Ş. (2009) Effects of Selective Withdrawal on Hydrodynamics of a Stratified Reservoir. Water Resour. Manage., 23, 1257-1273.

Caruso, B. S. (2004) Modeling Metals Transport and Sediment/Water Interactions in a Mining Impacted Mountain Stream. J. Am. Water Resour. Assoc., 40, 1603-1615.

Di Toro, D. M. (2001) Sediment Flux Modeling. John Wiley and Sons, Inc.: New York.

Elçi, S. (2008) Effects of Thermal Stratification and Mixing on Reservoir Water Quality. Limnology, 9 (2), 135-142.

Gualtieri, C. (2001) Comparison Between Water Quality Models for Toxics. Proceedings of the 1st Biennial Meeting of the iEMSs; Rizzoli, A. E., Anthony, J., Jakeman, A. J., Eds.; International Environmental Modelling and Software Society: Manno, Switzerland.

Hipsey, M. R.; Bruce, L. C.; Boon, L.; Bruggeman, J.; Bolding, K.; Hamilton D. P. (2012) GLM-FABM v0.9a Model Overview and User Documentaton; The University of Western Australia Technical Manual; The University of Western Australia: Perth, Australia.

Mutlu, Z. (2004) Geological Characteristics of Efemçukuru (Izmir); Thesis; Dokuz Eylul University, Department of Geological Engineering: Izmir, Turkey.

Ruiz, C. E.; Aziz, N. M.; Schroeder, P. R. (2001) RECOVERY: A Contaminated Sediment-Water Interaction Model. Environ. Model. Assess., 6 (3), 151-158.

U.S. Environmental Protection Agency (2005) Partition Coefficients for Metals in Surface Water, Soil, and Waste; Report No. EPA/600/R05/074; U.S. Environmental Protection Agency: Washington, D.C.

Yang, C. T. (2003) Sediment Transport: Theory and Practice; Krieger Publishing Company: Malabar, Florida. 